\title{
HEART DISEASE IN OLD AGE
}

\author{
F. I. CaIRD, D.M., M.R.C.P. \\ Radcliffe Infirmary, Oxford
}

IT is a truism that heart disease is one of the most important causes of morbidity and mortality in old age. Much of the morbidity and some of the mortality can without doubt be prevented by accurate diagnosis and correct treatment. It is upon these aspects of the cardiology of old age that this paper will concentrate, rather than on the problems of pathology and the natural history of heart disease, which will receive less attention than their intrinsic interest and importance merit.

\section{The Diagnosis of Heart Disease in the Elderly}

Two factors modify the cardinal symptoms of heart disease in old age. These are the mental manifestations of physical disease, which often obstruct history-taking and make physical examination difficult, and the almost invariable coexistence of several pathological processes in the same patient. Thus one symptom may have more than one simultaneous possible cause: breathlessness may be due to chronic lung disease, to obesity, or to anæmia, and ankle œdema to chronic venous insufficiency or hypoproteinæmia, rather than to heart disease. Expected symptoms may also be absent, as when activity is limited by arthritis, blindness, or hemiplegia.

By contrast, the majority of cardiovascular signs are little modified in old age. The arterial pulse is affected by the decreased elasticity of the large vessels so that the upstroke is more rapid and the peak systolic pressure higher (Wiggers, 1932). The apex beat is frequently displaced by chest deformity due to osteoporotic kyphoscoliosis, so that its site is not necessarily evidence of heart size. But the interpretation of the venous pressure and pulse remains the same as in youth, except when an elongated and unfolded aorta obstructs the left innominate vein and thus venous return from the left side of the neck (Shirley-Smith, I960; Sleight, 1962). The character of the apical impulse can usually be identified, and left ventricular hypertrophy correctly diagnosed. In particular, auscultatory signs carry the same connotation at all ages, and should therefore receive especial attention. Atrial and ventricular gallop sounds and respiratory variation in splitting of the second heart sound can be recognized. Pansystolic and all diastolic murmurs are abnormal at any age, but the characteristic aortic ejection murmur of old $\stackrel{\mathbb{2}}{\stackrel{2}{0}}$ age may give rise to difficulty. This murmur is $\%$ discussed in connection with aortic stenosis.

The electrocardiogram is of great assistance in $\vec{\overrightarrow{ }}$ diagnosis in the elderly, since any abnormality in $\vec{\omega}$ it, other than positional changes and the occasional ectopic beat, is as abnormal as at any age, and $\frac{0}{3}$ carries an adverse prognosis (Fox, 1944). Radiology plays a less important part, since the quality of radiographs obtained in ill old people is often not c్ high, and the interpretation of even technically adequate films not easy. Alteration of the $\infty$ position of the heart associated with chest de- O formity is the most important cause of difficulty; it may give rise to prominence of the main pul- $c$ monary artery, apparent left ventricular enlargement, and obscuration of the costophrenic angles. $\vec{\theta}$ Curious appearances may result from calcificatiog in costal cartilages, spinal ligaments, the annulus. fibrosus, and the aorta. Nevertheless, in mari cases characteristic radiological appearances cañ be recognized, and are then of diagnostic value.

Other investigations may be of assistance. A $\stackrel{\circ}{\circ}$ low peak expiratory flow rate may help to identify cor pulmonale due to chronic bronchitis, and the $\overrightarrow{0}$ same diagnosis may be suggested by the finding of a high serum bicarbonate, and proved by demonstration of an elevated arterial $\mathrm{PcO}_{2}$, either by the rebreathing method (Campbell and Howell, I960) or by blood gas analysis. The appropriate tests will be indicated if anæmia, uræmia, thyrotoxicosis, or bacterial endocarditis is suspected.

\section{Disorders of Cardiac Rhythm}

The two important arrythmias in the elderly are atrial fibrillation and ventricular tachycardia, though the occurrence of paroxysmal atrial tachycardia with block as a manifestation of $N$ digitalis intoxication (Lown and Levine, I955) N must be remembered.

Atrial fibrillation occurs in some 3 to $4 \%$ of otherwise 'normal' old people (Fisch, Genovese, Dyke, Laramore and Marvel, 1957), and in 1o to $15 \%$ of old people in hospital (Wosika, Feldman, $\mathbb{D}$ Chesrow, and Myers, I950). It is not clear whether coronary artery disease should be considered as its real causes, since fibrillation is often the only abnormality on the electrocardiogram. 
Atrial fibrillation is not infrequent in the course of acute infections and in association with surgical operations; it is then usually coterminous with its cause. It is also common in association with heart failure, especially in rheumatic heart disease (Bedford and Caird, 1956, 1960), with thyrotoxicosis and with pulmonary embolism, and may complicate acute myocardial infarction. But it is often also an incidental finding, and then the ventricular rate is usually not raised. Digitalis need only be given when there is tachycardia or heart failure, and intravenous digitalization should only rarely be used. When fibrillation outlasts an acute cause, or when its onset has been associated with the development of heart failure, consideration should be given to an attempt at conversion to sinus rhythm with quinidine, after a preliminary seven to ten days' course of anticoagulants to lessen the risk of systemic embolism.

Ventricular tachycardia is probably the commonest regular tachycardia in the elderly. It is usually associated with severe ischæmic heart disease or recent myocardial infarction, and results in hypotension and signs of a low cardiac output. It is best terminated by procaine amide, given slowly intravenously in a dose of up to I g., under continuous electrocardiographic control. To prevent recurrence, oral procaine amide should be given in doses up to $3 \mathrm{~g}$. per day.

Some 5 to $20 \%$ of 'normal' old people show prolongation of the $\mathrm{P}-\mathrm{R}$ interval (Fisch and others, 1957). Complete heart block is comparatively uncommon; it was found in six of 229 elderly patients with congestive failure (Bedford and Caird, 1956), and may precipitate failure in some cases. Steroids may be of benefit when complete heart block complicates acute myocardial infarction (Dall and Buchanan, 1962), but the conduction disturbance is then often transient (Penton, Miller and Levine, 1956). When heart failure is intractable or Stokes-Adams attacks frequent and uncontrolled by drugs, some form of cardiac pace-making should be considered whatever the age of the patient (Portal, Davies, Leatham and Siddons, 1962). But it must be remembered that complete heart block may be present for many years without symptoms and without treatment.

\section{Ischæmic Heart Disease}

Ischæmic heart disease is undoubtedly the most important single form of heart disease encountered in the elderly, both by itself and as contributing to the occurrence of cardiac symptoms in patients with valvular and other forms of heart disease. It shows certain interesting differences from the pattern seen in middle age. The most striking epidemiological fact is the steady increase with age in the incidence of ischæmic heart disease ac- companied by a steady decrease in the preponderance of men. This is shown in all clinical and autopsy studies, and is attributed to a protective influence of the female sex hormones, a view supported by the high incidence of ischæmic heart disease in oophorectomized women (Oliver and Boyd, 1959). Pathologically a similar trend is seen in the incidence and sex ratio of large myocardial lesions, both necrotic and fibrotic, which may legitimately be termed infarcts (Mitchell and Schwartz, 1962). These lesions are closely related to the degree of coronary arterial stenosis. Other smaller myocardial lesions, which are usually thought to be ischæmic in origin, are more closely related to age than to coronary artery disease, and show a more nearly equal sex ratio at all ages (Schwartz and Mitchell, 1962). The functional significance of these smaller lesions is not clear, but it is possible that they contribute more to the incidence of heart failure in old age than the larger ones. Certainly congestive failure in the elderly is not much commoner in men than women (Bedford and Caird, 1956), and is poorly related to the severity of coronary artery disease (Rose and Wilson, 1959).

From the clinical standpoint, there are few clear differences between ischæmic heart disease as it occurs in the elderly and the middle-aged. The most definite is the lesser severity of cardiac pain in old age, a phenomenon which cannot be attributed to mental dulling. Angina pectoris may be described as mere tightness in the chest, and the pain of cardiac infarction, though no different in distribution or character, is often surprisingly mild. Other manifestations such as breathlessness or mental or neurological symptoms due to cerebrovascular insufficiency may dominate the picture. The clinical signs of cardiac ischæmia giving rise to angina are often slight at any age, and those of acute myocardial infarction may be difficult to detect. Especial note must be made of slight elevation of the venous pressure with a positive hepatojugular reflux, of left atrial or ventricular gallop rhythm, and of the sudden development of heart failure in a patient with previously good exercise tolerance. Fever, leucocytosis, and elevation of the erythrocyte sedimentation rate and serum transaminase are as valuable in old age as earlier in life as indications of myocardial infarction, if other causes can be excluded, but the electrocardiogram is the mainstay of diagnosis.

Few of the complications of myocardial infarction increase in frequency with age except rupture of the heart (Sievers, Blomqvist, and Bjorck, 1961). But most hospital series show a steady rise in mortality with age, so that in the ninth decade $60 \%$ or more of those with myo- 
cardial infarction die (Bjorck, 1962). However, routine electrocardiographic and autopsy studies (Fisch and others, 1957; Gould and Cawley, 1958) show an incidence of totally unsuspected past myocardial infarction of $5 \%$ in the elderly. The prognosis of myocardial infarction in old age must be much better than hospital series indicate. The long-term survival of elderly patients is undoubtedly better, relative to their expected mortality, than that of younger patients with myocardial infarction. Thus Bjorck, Sievers and Blomqvist (1958) found the ratio of actual to expected mortality over a five-year period to be 4.6 in men in the sixth decade and 1.3 in the ninth.

The management of ischæmic heart disease in old age must take these facts into account. Angina should be treated with trinitrin and limitation of activity to within the bounds set by the symptom. In acute myocardial infarction bed rest need not be prolonged beyond the first few days unless there is hypotension or gross asthenia. If anticoagulants are given it should be in the knowledge that their main function is to prevent venous thrombosis and pulmonary embolism during the acute stage (Honey and Truelove, 1957). They have little place in the long-term management of ischæmic heart disease in old age (McMichæl and Parry, I960).

\section{Hypertension}

The range of variation of blood pressure in healthy old people is wide. Systolic pressures of up to $210 \mathrm{~mm}$. $\mathrm{Hg}$ and diastolic pressures of I $10 \mathrm{~mm}$. $\mathrm{Hg}$ can be regarded as the upper limits of normality (Master, Lasser, and Jaffe, 1958; Anderson and Cowan, 1959). Symptoms should therefore not be attributed to hypertension in old age when the blood pressure is below these levels. Only benign hypertension requires consideration since malignant hypertension with papillœdema is very rare over the age of 70 (Kincaid-Smith, McMichael, and Murphy, r 959). It is usual to regard all hypertension in the elderly as 'essential' in type, but it is possible that in more cases than is suspected at present it is due to chronic renal disease, in particular chronic pyelonephritis. Evidence of active chronic pyelonephritis can often be adduced when the blood pressure is found to have risen considerably in a period of months or a few years.

As in younger subjects, benign hypertension in old age has few true symptoms. Great care should be taken in ascribing any symptoms other than those of heart failure to elevation of the blood pressure. Minor symptoms such as headache and dizziness are rarely if ever due to hypertension, while angina pectoris and strokes are attributable to associated vascular disease.

In the absence of heart failure, evidence that hypertension is harming the patient may be found in left ventricular hypertrophy, demonstrable clinically, electrocardiographically, or radiologically, in reversed splitting of the second heart sound, and in left atrial or ventricular gallop rhythm. The fundi show increased tortuosity of the retinal arteries, but only rarely hæmorrhages or exudates. Pyuria may indicate underlying pyelonephritis, and should be treated with the antibiotic appropriate to the organism cultured from the urine. Further detailed investigation to exclude renal disease is rarely justifiable, since it must be quite exceptional to find any unilateral renal disease suitable for surgical treatment in an elderly patient.

The indication for treatment of hypertension in old age is heart failure. This should be treated along the usual lines with digitalis and diuretics. Hypotensive therapy should be restricted to patients with gross elevation of the diastolic pressure which persists after resolution of heart failure. In general only reserpine in combination with a thiazide diuretic should be used, although the occurrence of depression due to reserpine and diabetes due to thiazides may necessitate a change of treatment. There is virtually no indication for the use of powerful hypotensive agents such as ganglion-blocking drugs or guanethidine, though methyldopa may be found to have a place. Cerebrovascular disease of any severity is a contra-indication to active treatment, since severe symptoms may be precipitated by lowering the blood pressure. This is especially true of the form of hypertensive cerebrovascular disease causing dementia, especially in elderly men (Hughes, Dodgson, and MacLennan, 1954). Angina pectoris is no contra-indication of itself, but is rarely relieved by treatment of hypertension.

Bechgaard (1946) found that diastolic pressures of up to $120 \mathrm{~mm}$. Hg do not carry any increased mortality over the age of 70 . This is to be expected if such pressures are regarded as normal. For diastolic pressures over this figure, the excess mortality of male hypertensives persists into old age. Surprisingly, the mortality of hypertensive heart failure is greater in women than in men (Clawson, I95I ; Bedford and Caird, 1956).

\section{Rheumatic Heart Disease}

It is now clear that rheumatic heart disease is common in the elderly, and that the diagnosis is often not made because it is not thought possible. The incidence in elderly hospital patients is around $4 \%$ (Bedford and Caird, 1960) and is little less in the general population (Muller, 1956). 


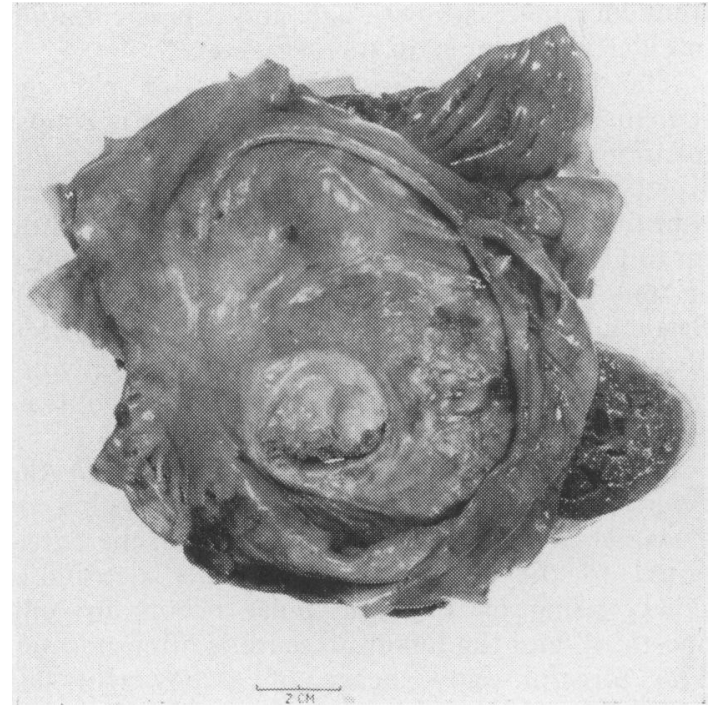

FIG. I.-Severe mitral stenosis in a 69 -year-old woman.

There is little doubt that this high incidence is due to the great prevalence of acute rheumatism during the childhood and adolescence of those now over 60 and to the survival of many sufferers from the less severe forms of the disease. The following account is based on a study of 126 patients over the age of 65 (Bedford and Caird, 1960).

About $40 \%$ of elderly patients with rheumatic heart disease give a history of rheumatic fever or chorea in childhood or adolescence. In one-third of all cases the dominant lesion of the mitral valve is stenosis, not infrequently severe (Fig. I); in the remainder incompetence predominates (Fig. 2). About one-half of all patients have disease of the aortic valve; this consists of incompetence alone in two-thirds (Fig. 3), stenosis and incompetence in $25 \%$, and pure stenosis in $15 \%$. Pure rheumatic aortic incompetence and all forms of organic disease of the tricuspid valve are rare. In onethird of all patients there is atrial fibrillation, which is closely associated with heart failure.

The physical signs are much as in younger patients. In mitral stenosis a loud first sound is usual; when heard during tachycardia this should always indicate the need for careful search for other signs of mitral disease when the heart rate is slower. An opening snap is not frequent, and if present is not usually loud. The most valuable sign is a long apical mid-diastolic murmur with presystolic accentuation if sinus rhythm is present. Any evidence of right ventricular hypertrophy is rare. The electrocardiogram may show $\mathrm{P}$ mitrale, and a chest $\mathrm{X}$-ray evidence of left atrial enlarge-

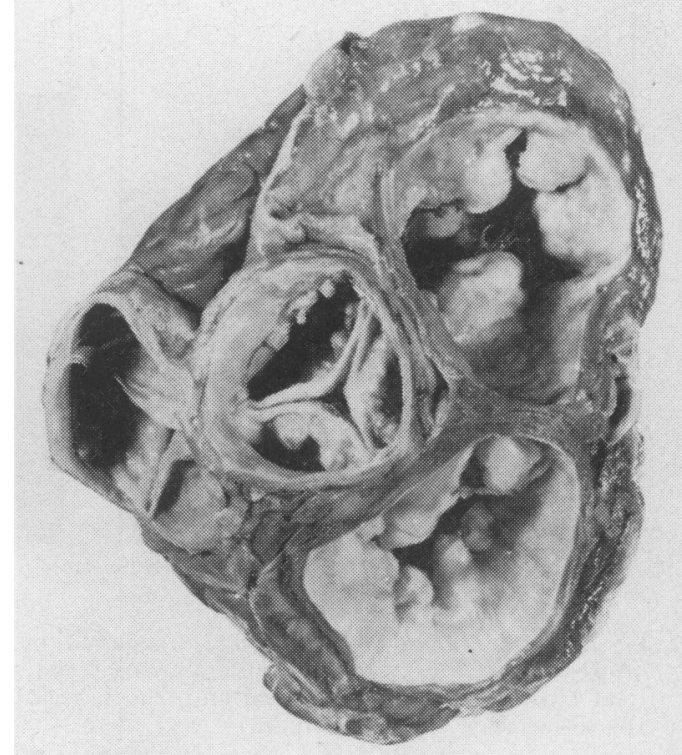

FIG. 2.-Mitral incompetence and calcareous aortic stenosis in a 78-year-old woman.

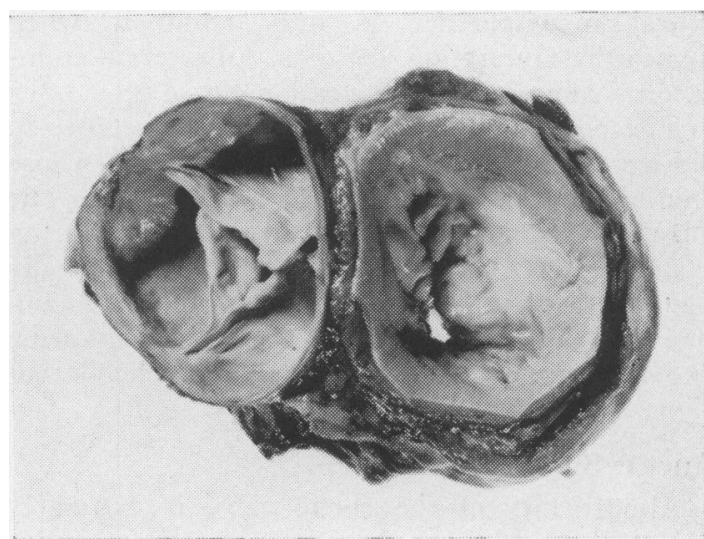

Fig. 3.-Mild mitral stenosis and severe aortic incompetence in a 96-year-old woman who had no cardiac symptoms.

ment. Kerley's lines are not common, and signs of pulmonary hypertension exceptional.

The usual signs of mitral incompetence are left ventricular enlargement, an apical pansystolic murmur, sometimes with a thrill, and an apical third heart sound followed by a short mid- 


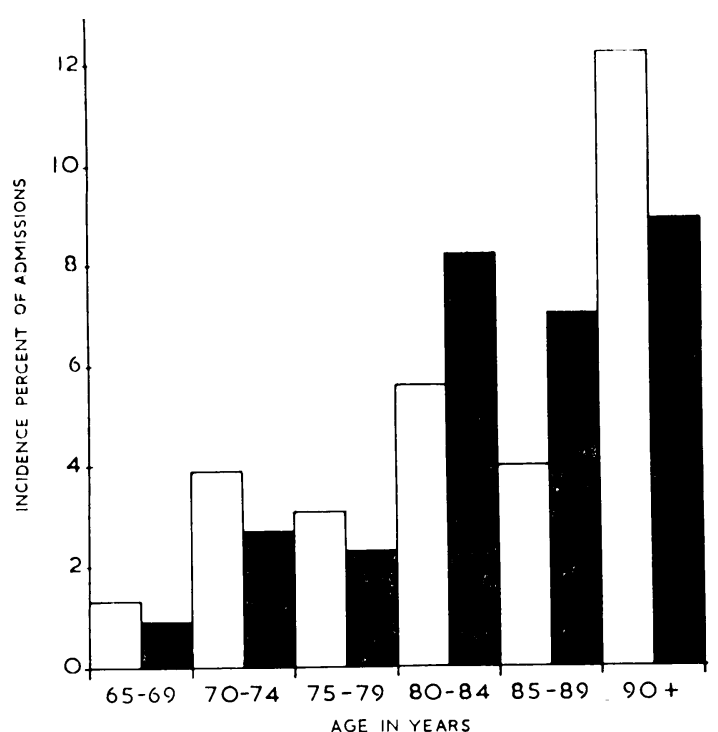

Fir: +.-Percentage incidence of aortic stenosis without mitral disease in $3,12+$ admissions to Cowley Road Hospital, Oxford (Bedford and Caird, r960). (Black-women. White-men.)

diastolic murmur. Radiology and electrocardiography are not often helpful.

The prognosis of rheumatic heart disease in old age is good unless there is atrial fibrillation or heart failure. Other complications are infrequent. Systemic embolism occurs in $20 \%$ of cases of mitral stenosis with atrial fibrillation, but in mitral incompetence is only common when myocardial infarction coexists. Bacterial endocarditis complicates the occasional case.

The occasional case of mitral incompetence in old age is due to an accessory mitral cusp, whose chordæ tendineæ stretch with age, allowing the cusp to prolapse into the left atrium during systole (Davis, 1962). In one case personally seen there was a very loud systolic murmur and thrill maximal internal to the apex. Tachycardia and tachypnoea made it impossible to elicit other signs.

\section{Aortic Stenosis}

Abnormality of the aortic valve is extremely common in old age. An aortic ejection murmur is present in two-thirds of subjects over the age of 70 (Bruns and van der Hauwert, $195^{8}$ ), and is probably due to fibrous thickening of the bases of the cusps, a condition usually termed aortic valvular sclerosis. True aortic stenosis, with obstruction to left ventricular ejection, and usually heavy calcification of the valve, is also common, being found in $4 \%$ of elderly hospital patients (Bedford and Caird, 1960) and in perhaps $3 \%$ of the general population (Muller, 1956). Its frequency increases with age, and it is as common in elderly women as in men (Fig. 4).

The atiology of aortic stenosis in old age remains disputed. According to some, it is almost invariably of rheumatic origin (Karsner and Koletsky, 1947), but others can demonstrate a continuum of changes in the aortic valve, leading up to gross stenosis, in which there is no evidence of any rheumatic process (Ashworth, I0 $4^{(6)}$. Bacon and Matthews ( 1959 ) consider a proportion of cases due to degenerative changes in congenital bicuspid valves. Each of these processes doubtless contributes some cases.

Aortic stenosis is often asymptomatic in the elderly, but in perhaps $40 \%$, dyspnoea, angina, or syncopal attacks, often exertional, can be attributed to the disease. A clinically detectable slowly rising or anacrotic pulse occurs in only one-third, and the blood pressure is often normai. The forceful, slow heave of a powerful left ventricle acting against an obstruction is often evident. The characteristic aortic ejection murmur may be clearly audible at the apex as well as the base of the heart, and is usually loud and harsh. 'There is a basal systolic thrill in one-third of cases. The aortic component of the second sound is in most cases softer than normal or than would be expected from the pulse pressure (Bedford and Caird, i 960) and reversed splitting of the second sound can often be demonstrated. In two-thirds of cases there is an aortic diastolic murmur, usually short and only audible at the base of the heart.

The electrocardiogram shows the changes of left ventricular hypertrophy, often with conspicuous $\mathrm{S}-\mathrm{T}$ depression and $\mathrm{T}$ wave inversion in the left precordial leads (Abdin, I958). Chest $\mathrm{X}$-rays confirm the presence of left ventricular enlargement, though this is rarely gross unless there is heart failure or considerable aortic incompetence. Calcification in the aortic valve may be shown on a good lateral radiograph, or demonstrated by screening or tomography (Davies and Steiner, 1949), but it must be remembered that calcification may well not always indicate actual stenosis of the aortic valve in the elderly.

Aortic stenosis must be distinguished from aortic valvular sclerosis. In both there is an aortic ejection murmur, but in the latter it is usually less loud and less harsh, and is only rarely accompanied by a thrill (Bruns and van der Hauwert, 1958). In aortic stenosis there is by definition obstruction to left ventricular outflow manifest by an anacrotic pulse or reversed splitting of the second sound, and some evidence of left ventricular hypertrophy, whether clinical, electrocardiographic, or radiological. These signs are absent in aortic valvular sclerosis, and in addition 


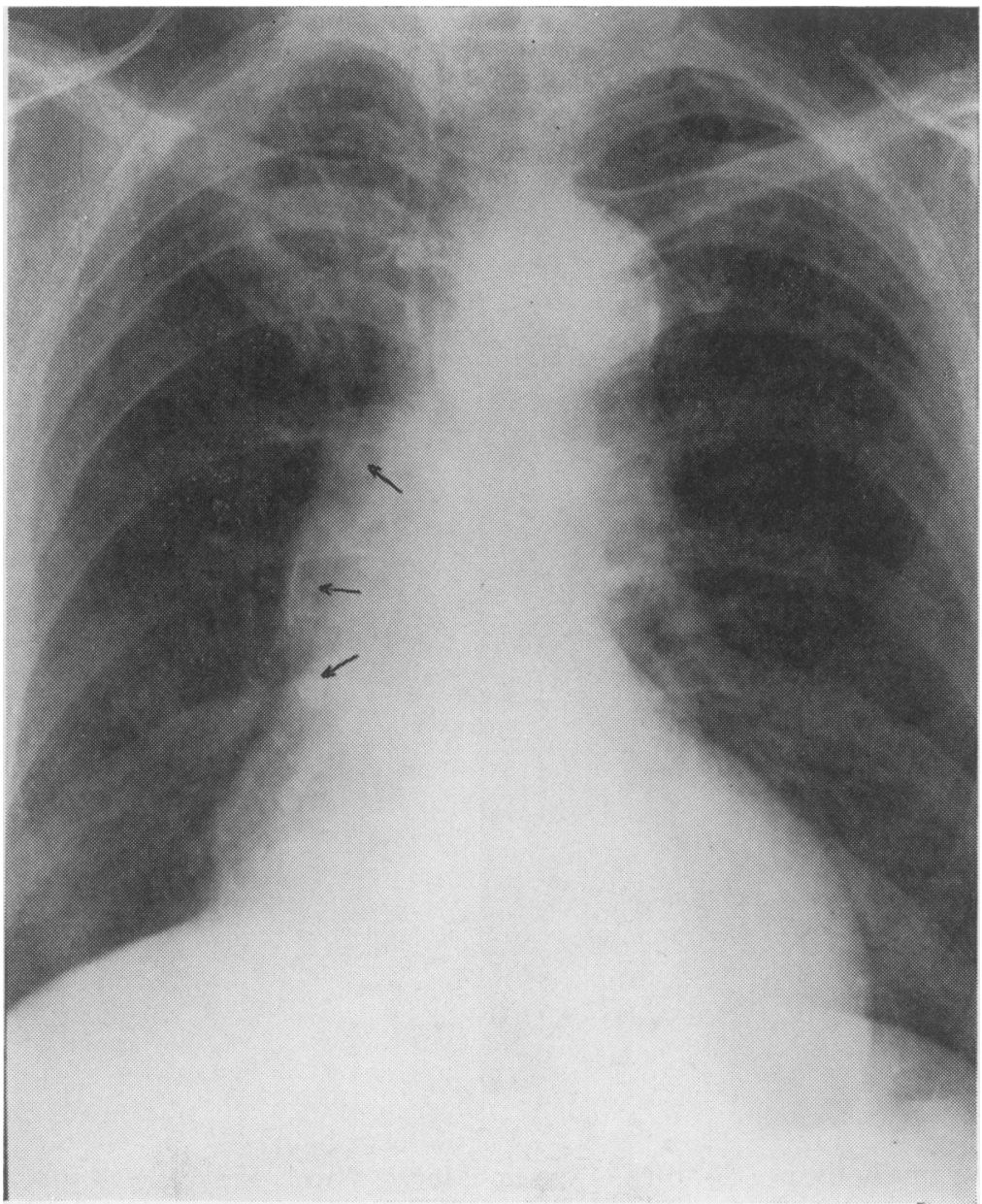

Fig. 5.-Calcification in ascending aorta in 74-year-old man with syphilitic aortic incompetence.

the aortic component of the second sound is of normal intensity. It is usually possible to make a firm diagnosis, if attention is paid to detail.

The prognosis of aortic stenosis in old age is good if there are no symptoms. When there is heart failure it is little worse than when failure is due to other causes (Bedford and Caird, 1960). Anderson, Kelsey and Edwards (1952) think that major surgical operations may carry an extra risk in patients with aortic stenosis, but personal experience does not bear this out.

\section{Aortic Incompetence}

Aortic incompetence has many causes, most of them very rare in the elderly. These include rupture of an aortic cusp (Carroll, I95 I); bacterial endocarditis; dissecting aneurysm of the aorta (Levine, Stein, Gordon and Mitchell, 195I); incomplete aortic rupture (Peery, I942), in which a tear in the aortic intima just above the aortic valve allows the adjacent cusp to prolapse into the left ventricle in diastole; giant-cell (temporal) arteritis; and aortitis in ankylosing spondylitis (Clark, Kulka, and Bauer, 1956). There are four common causes: rheumatic endocarditis and calcareous disease of the aortic valve, already discussed; syphilitic aortitis; and isolated nonsyphilitic aortic incompetence' (Bedford and Caird, 1960), a term preferable to 'functional' or 'arteriosclerotic' aortic incompetence.

\section{Syphilitic Aortic Incompetence}

Syphilitic heart disease is now comparatively uncommon at any age, but in recent series about onethird of cases have been over 60 years of age (Macfarlane, Swan, and Irvine, 1956; Leonard and Smith, 1957). It is commoner in old men than in old women, and rare over the age of 80 (Bedford and Caird, 1960).

In the elderly a past history of syphilis is often unobtainable, but there is clinical evidence of neurosyphilis, usually tabes or tabo-paresis, in 


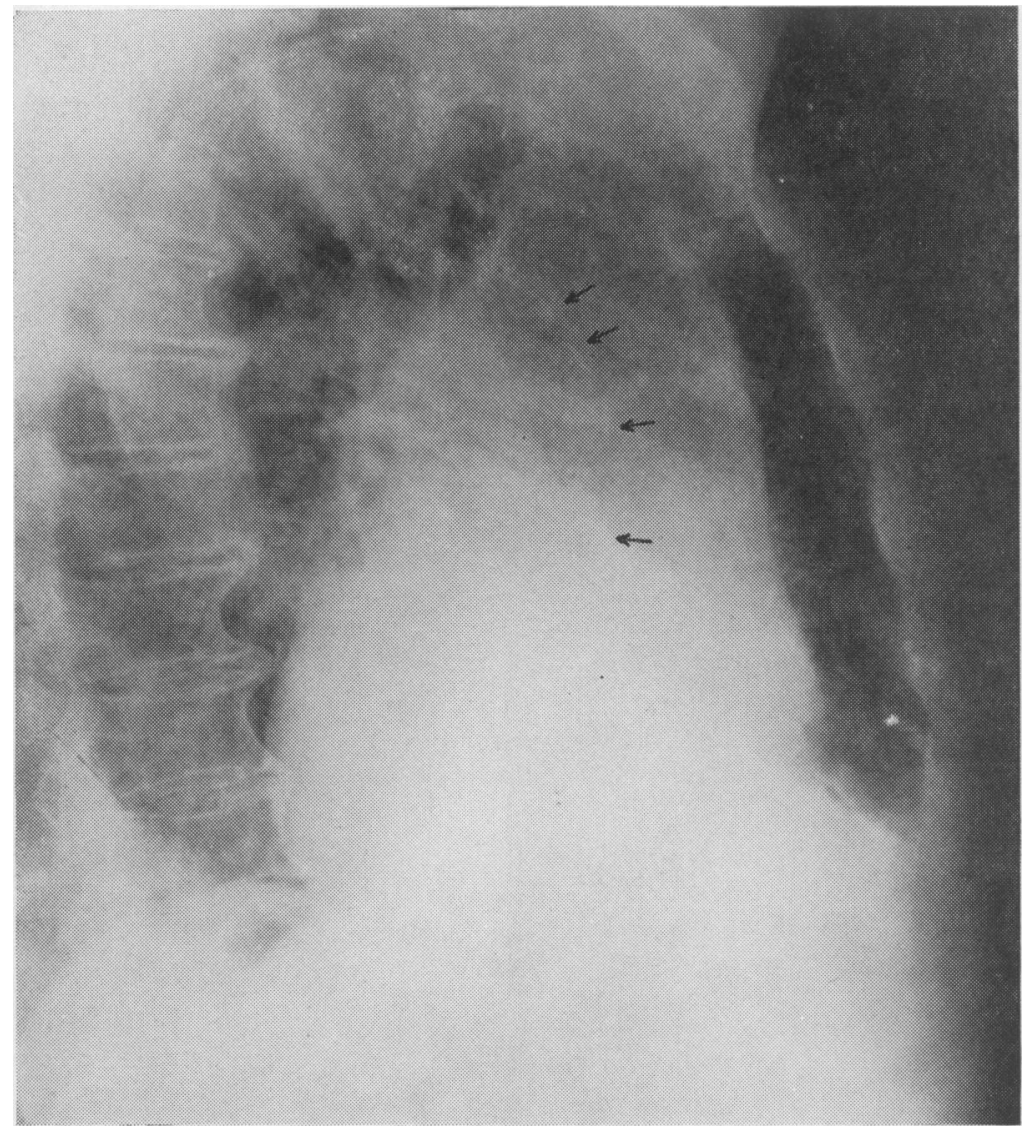

Fig. 6.-Lateral chest X-ray of same patient as in Fig. 5 .

many cases. Cardiac symptoms-angina or dyspnœa-are frequent. A collapsing pulse, high pulse pressure, and considerable left ventricular enlargement are evidence of severe aortic incompetence in many cases. An aortic ejection murmur is the rule, but a basal systolic thrill is uncommon (Leonard and Smith, 1957). The aortic second sound is often loud and ringing, and the aortic diastolic murmur long and widely heard over the præcordium.

Radiology is of great value, since irregular dilatation of the aorta, and calcification in its ascending part can often be demonstrated, especially in lateral views, and are almost pathognomic, at least under the age of 80 (Thorner, Carter, and Griffiths, 1949; Figs. 5 and 6). The electrocardiogram shows evidence of left ventricular hypertrophy or myocardial ischæmia (Storey, 1958). The serological tests for syphilis are positive in blood or cerebrospinal fluid in the great majority of cases, or will be known to have been positive in the past.

The prognosis of asymptomatic syphilitic aortic incompetence is not unduly poor (Webster,
Rich, Densen, Moore, Nicol, and Padget, 1955). But when heart failure is present in the elderly, the outlook is worse than in other varieties of heart disease (Bedford and Caird, 1956). Penicillin therapy should be given if there is evidence of active infection (the quantitative Kahn test is most useful), though it must be admitted that there is little proof that it is beneficial. Iodides would seem unnecessary, and undue fear of the JarischHerxheimer reaction unreasonable.

\section{Isolated Aortic Incompetence}

It has long been recognized that aortic incompetence in old age may not be due to any of the commoner causes and may lack a clearly defined pathological basis. The underlying cause in these cases seems to be dilatation of the aorta (Gouley and Sickel, 1943; Bedford and Caird, 1960), not necessarily in association with hypertension and in the absence of any abnormality of the aortic valve. This dilatation is a normal accompaniment of ageing (Suter, 1897; Fig. 7), and has been demonstrated in life by angiocardiography (Dotter and Steinberg, 1949). With it goes a decrease in the 


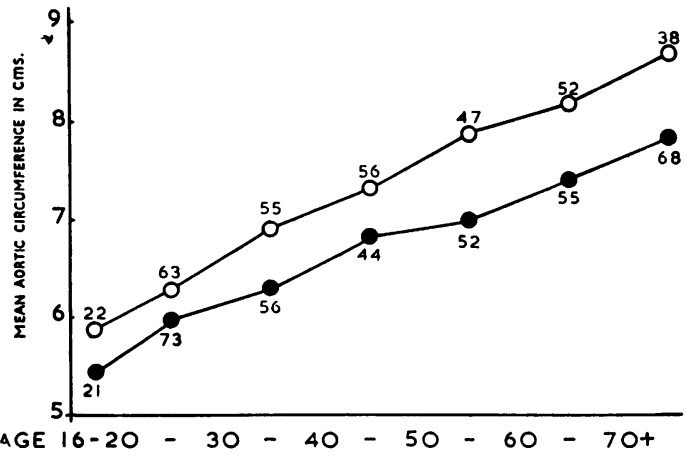

FIG. 7.-Relation between mean circumference of aortic ring and age (Suter, 1897). Upper line (open circles) men of 161 to $165 \mathrm{~cm}$. body length, lower line (closed circles) women of I I I to I $55 \mathrm{~cm}$. body length. Figures by each point indicate number of subjects in each group.

elasticity of the aortic media (Wilens, 1937), and, according to some, histological changes in the medial elastic tissue (Hass, 1942, 1943).

Clinically the condition is usually asymptomatic, and heart failure is no more frequent than in elderly patients with a normal aortic valve. The aortic incompetence is most often slight, and does not give rise to a collapsing pulse or left ventricular enlargement. The blood pressure varies, but is often normal (Fig. 8). There is usually an aortic. ejection murmur, which is soft and not accompanied by a thrill. The early diastolic murmur is usually short and only heard at the base or apex of the heart. Radiology does not contribute, as the degree of aortic dilatation is rarely great enough to be recognizable. Electrocardiography is also unhelpful. The condition has a good prognosis.

Rheumatic aortic incompetence may be distinguished by the presence of signs of disease of the mitral valve, calcareous aortic valve disease by the harsher systolic murmur and reduced intensity of the aortic component of the second sound, and syphilitic aortic incompetence by the presence of signs of neurosyphilis, the usually severe aortic incompetence, and the positive serology. The rarer causes may give rise to difficulty, and there will inevitably be errors, but attention to the points mentioned will allow a correct diagnosis in the great majority of cases.

\section{Pulmonary Embolism}

Pulmonary embolism is extremely common in old age. It was found in $30 \%$ of unselected autopsies in the eighth and in $4 \mathrm{r} \%$ in the ninth decade (Towbin, 1955). It is particularly associated with heart failure (Bedford and Caird, 1956, 1960), obesity, fractured femur (Sevitt and
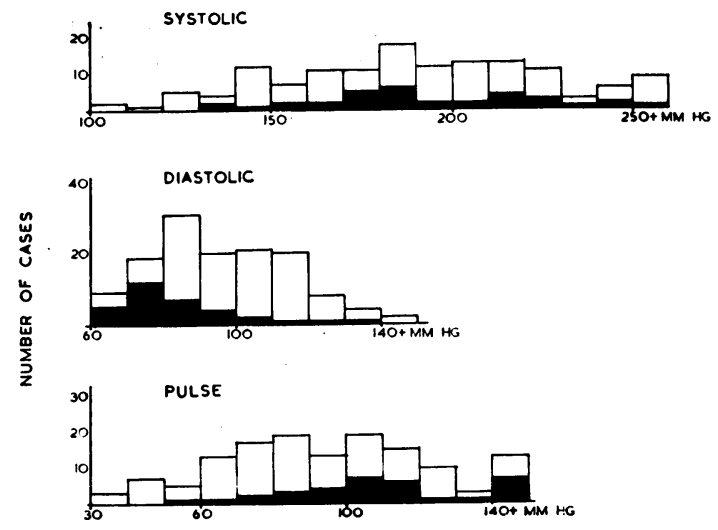

FIG. 8.-Distribution of systolic, diastolic and pulse pressures in 134 patients with isolated aortic incompetence (Bedford and Caird, 1960). Black areas indicate patients with collapsing pulse.

Gallagher, 1959), varicose veins (as a sign of chronic disease of the leg veins rather than as a direct source of emboli), and hemiplegia (Byrne and O'Neil, 1952).

The clinical features of pulmonary embolism are very varied and in the elderly diagnosis may be especially difficult. In old age the most frequent symptom is sudden tachycardia and tachypnœa, which may be paroxysmal and thus mimic left ventricular failure. Pleurisy with hæmoptysis is relatively uncommon, but if hæmoptysis occurs, it is often persistent or recurrent. The presence of fresh blood in mucoid sputum is characteristic. In massive pulmonary embolism, collapse, with neurological signs due to cerebrovascular insufficiency, is frequent.

The most important physical signs are otherwise inexplicable tachycardia, often irregular due to atrial fibrillation, and unresponsive to digitalis, elevation of the venous pressure, right ventricular or right atrial gallop rhythm, and signs of a local lung lesion-pleural friction, consolidation, or effusion. Calf pain and tenderness are not frequent as signs of venous thrombosis, but if present are of great diagnostic importance. Commoner signs are œedema and increased warmth, often slight, of one foot or leg, dilatation of superficial veins, and greater swelling of one leg than the other.

In patients with heart failure, the usual clinical pattern of pulmonary embolism consists of sudden deterioration of the failure, with simultaneous increase in pulse and respiratory rates and in venous pressure. There may be intensification of local signs over one area of lung, or development of a pleural effusion, only rarely bloodstained, or unilateral enlargement of one of 
bilateral effusions. Fever in heart failure is often due to pulmonary embolism (Kinsey and White, I943), as is the triad of tachycardia, digitalis toxicity, and resistance to diuretics (Tench, 1955).

Chest X-rays may show wedge-shaped, linear, or ill-defined opacities, or a pleural effusion, but signs of heart failure may obscure the picture (Short, 1951).

There is also a variety of electrocardiographic patterns (Cutforth and Oram, 1958). The $\mathrm{S}_{1} \mathrm{Q}_{3} \mathrm{~T}_{3}$ pattern is not infrequent, and especial attention should be paid to $\mathrm{T}$ wave inversion in leads $V_{3}$ and $V_{4}$. But these important signs of pulmonary embolism may well be lacking if the embolus is small or may be masked by preexisting abnormality of the electrocardiogram.

Early ambulation may be expected to assist in preventing pulmonary embolism in old age, but it is reasonable to give anti-coagulants to patients at especial risk, despite the difficulties in the control of this treatment in the elderly (Bedford and Caird, 1960). Anti-coagulants have been shown to reduce the mortality of congestive heart failure (Griffith, Stragnell, Levinson, Moore, and Ware, 1952), and of fractured femur (Sevitt and Gallagher, 1959). They should therefore be considered as part of the routine treatment of these conditions, as well as in patients with clinically obvious leg-vein thrombosis or pulmonary infarction.

\section{Chronic Pulmonary Heart Disease}

Chronic pulmonary heart disease is not common over the age of 75 (Flint, 1954), but under that age is an important cause of heart failure, especially in industrial areas. The underlying lung disease is almost always chronic bronchitis with or without emphysema. The diagnosis is made from the long history, often of 40 or more years, of cough and phlegm, with winter exacerbations and wheezing. The signs of peripheral vasodilation and right ventricular hypertrophy are not as prominent as in younger patients, but central cyanosis, regular tachycardia, and right-sided gallop rhythm are usual. Expiratory obstruction is indicated by tracheal wheeze, a positive phase in the venous pressure during expiration, and a very low peak expiratory flow rate ( $100 \mathrm{l} / \mathrm{min}$. or less). Chest radiographs show some slight enlargement of the heart, with prominence of the main pulmonary arteries. The elctrocardiogram shows $P$ pulmonale, a vertical heart with right axis deviation, and signs of right ventricular hypertrophy (a dominant $R$ wave in leads $V R$ or $V_{4} R$, or dominant $\mathrm{S}$ in $\mathrm{V}_{5}$ ). Routine treatment of heart failure together with intensive and prolonged antibiotic therapy often produces remarkable improvement, but the prognosis is not good (Bedford and Caird, I956).

The occasional case of cor pulmonale secondary to chronic diffuse interstitial fibrosis of the lungs $\unrhd$ (Scadding, 1960) may be recognized by a com- $\varsigma$

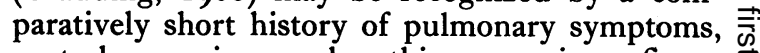
central cyanosis, over-breathing, prominent finger clubbing, and coarse basal râles. In a further small number of cases, evidence of venous disease in the legs, and considerable right ventricular hypertrophy with $\mathrm{T}$ wave inversion in the right precordial leads, indicate thrombo-embolic cor pulmonale (Goodwin, Harrison, and Wilcken, $\vec{\circ}$ 1963); anticoagulant therapy is then essential.

\section{Miscellaneous Forms of Heart Disease Congenital Heart Disease}

Of all the forms of congenital heart disease only atrial septal defect has a good enough prognosis to be other than very rare in old age, although the occasional case of patent ductus arteriosus and of coarctation of the aorta should not escape the clinician aware of the possibility of their existence. The clinical, radiological, and electrocardiographic picture of atrial septal defect in old age is essentially similar to that seen in younger patients, apart from the frequent occurrence of atrial fibrillation (Colmers, 1958). Other conditions, such a hypertension, may mask the characteristic patter of incomplete right bundle branch block in the electrocardiogram. Particular mention may be made of the combination of very large pulmonary arteries and evidence of increased pulmonary vascular markings on the chest X-ray (Colmers, 1958), as these are otherwise rare in old age.

\section{Bacterial Endocarditis}

In recent years, as many as one-sixth of cases of bacterial endocarditis have been over 60 years of age (Anderson and Staffurth, I955; Wedgwood, I956), The causative organism is usually $S$. viridans, though endocarditis due to $S$. faecalis or $E$. coli may follow operations on the urinary tract, and the occasional case of staphylococcal endocarditis is seen, often presenting with signs of meningeal involvement.

The diagnosis of bacterial endocarditis is often missed in the elderly, even in the face of classical manifestations because it is not thought of (Anderson and Stafforth, 1955). In some cases progressive renal failure may be the presenting feature (Zeman, 1945), in others prominent mental symptoms (Gleckler, 1958). But, as in the young, the occurrence of fever in a patient with valvular disease, with systemic embolism, splenomegaly, or clubbing of the fingers, should be an indication for a blood culture, however many other possible causes of these symptoms and signs may be 
present. Nor should features such as atrial fibrillation and congestive heart failure, which are said to be rare in bacterial endocarditis, deflect thought from the diagnosis. 'Treatment should be as intensive as in the young, for if the prognosis is bad in old age (Cates and Christie, I95I), the main cause is without doubt delay in diagnosis, and the high incidence of heart failure, rather than the ineffectiveness of treatment.

\section{Thyrotoxic Heart Disease}

It is well known that in old age it is the cardiac rather than the metabolic or ocular manifestations of thyrotoxicosis that dominate the clinical picture. Although, as in younger patients, organic heart disease often underlies this cardiac response to thyrotoxicosis, there is little doubt that heart failure may occur in a basically normal heart (Sandler and Wilson, 1959).

In old age the diagnosis of thyrotoxic heart disease is suggested by cardiac symptoms with weight loss, restlessness, a warm skin, or tachycardia (often with atrial fibrillation) unresponsive to digitalis, and a goitre. There may, of course, be evidence of ischæmic, valvular, or pulmonary heart disease in addition.

The diagnosis is best confirmed by a radioiodine uptake test or by the estimation of plasma protein-bound iodine, since the basal metabolic rate is often technically difficult to estimate or to interpret, especially if heart failure is present. A therapeutic test with anti-thyroid drugs is also of great value. Radio-iodine is the most satisfactory definitive therapeutic measure (Sandler and Wilson, 1959), but surgery may be needed if the goitre is large or retrosternal, or if rapid control of thyrotoxicosis seems essential.

\section{Beri-beri Heart Disease}

Heart failure due to beri-beri is occasionally seen in elderly patients who live in poor circumstances on a very defective diet. There is evidence of a high output state with a regular tachycardia, warm extremities, and full peripheral veins. The electrocardiogram shows widespread inversion of $\mathrm{T}$ waves (L. Wollner, personal communication). The clinical picture is completed by a rapid response to parenteral vitamin $B_{1}$.

\section{Anamia}

Anæmia of all kinds is common in old age, but is comparatively rare even as a contributory cause of congestive heart failure (Bedford and Caird, 1956). When it does cause failure, the prognosis is that of the anæmia rather than of the failure.

The importance of the cardiac manifestations of severe anæmia in the elderly lies in the urgency of treatment, which must be begun as soon as a hæmatological diagnosis has been made. Patients with megaloblastic anæmia should receive the appropriate hæmatinic. Those with anæmias of other origin usually require transfusion, and this should not be withheld because of any supposed ill-effects of transfusion in old age, even if heart failure is present. Acute pulmonary œdema during blood-transfusion in severe anæmia (Sharpey-Schafer, 1945) occurred in patients receiving blood at the very rapid rate of $500 \mathrm{ml}$. in 12 to 40 minutes. Packed red cells given at a reasonable rate (e.g. cells from I litre in 6 to 8 hours) are extremely well tolerated. Such small slow transfusions may need to be repeated every two or three days until a hæmoglobin level of $10 \mathrm{~g} / 100 \mathrm{ml}$. is reached and maintained. Acute symptoms developing during transfusion are as likely to be due to a febrile reaction as to circulatory overload, and respond to slowing of the drip rate and intravenous aminophylline.

\section{Heart Failure}

The proper management of heart failure in old age begins with proper diagnosis. In the elderly, the presenting symptoms of heart failure differ from those in younger patients. Although breathlessness is always demonstrably present, it is often overshadowed by confusion, restlessness, cough, wheezing, weakness, anorexia, nausea, or abdominal pain.

The diagnosis of congestive heart failure rests on the simultaneous presence of dyspnœa, elevation of the venous pressure in all phases of respiration (or a positive hepato-jugular reflux (Matthews and Hampson, 1958)), bilateral basal râles, hepatomegaly, and systemic œdema. Only if all these signs are present is the diagnosis correct. Left heart failure cannot be so precisely defined clinically, but paroxysmal nocturnal dyspnœa, orthopnœa, and gross limitation of exercise tolerance (e.g. dyspnœa on moving in bed, or on talking) together with left ventricular enlargement and left ventricular gallop rhythm, will be present in almost all cases. There may be an obvious cause of left ventricular failure, such as myocardial infarction, hypertension or aortic valve disease.

The principal differential diagnosis is from pulmonary disease and other causes of œdema. Acute primary broncho-pulmonary diseases such as broncho-pneumonia and aspiration-collapse of the lung may be suggested by fever, evidence of recent upper respiratory tract infection, and purulent sputum, more chronic conditions such as bronchiectasis by a long history of productive cough and recurrent chest illnesses, purulent sputum, and perhaps finger clubbing. In neither group of conditions is there orthopnœa unless 
respiratory failure is extreme or heart failure present. Other causes of œdema are distinguished by a normal venous pressure.

Special investigations contribute very little to the diagnosis of heart failure, except that chest $\mathrm{X}$-rays may show the 'butterfly' pattern of pulmonary œdema, Kerley's lines, cardiomegaly, or pleural effusion. The proper place for the diagnosis is the bedside.

The treatment of heart failure in old age is based, as it is in younger patients, on rest, digitalis, oxygen, salt restriction, and diuretics. If possible, the precipitating cause of failure should be treated. The prevention of pulmonary embolism is of such importance that the routine use of anticoagulants is certainly justifiable, and should be considered whenever facilities permit.

In the management of heart failure, rest does not necessarily mean rest in bed; a comfortable arm-chair may be more satisfactory. Adequate sleep is vital, and is best achieved by rapid control of failure. Oxygen often helps to control restlessness. Any drugs used must be simple, such as alcohol or chloral, though it is certainly permissible to give small doses of morphine to patients who are not confused. Digitalis should rarely need to be given intravenously, and the sensitivity of the elderly to the drug should always be remembered. Numerous ectopic beats are an indication for reduction in dose, as well as the more usual signs of toxicity. Salt restriction is of great importance, but should rarely be drastic The simple regime described by Bedford (1950) is valuable for the first few days. The thiazide diuretics are entirely adequate in most elderly patients, though one or two injections of a mercurial may be given to initiate treatment. The risk of producing acute retention of urine in elderly men must be accepted; normal micturition can usually be re-established after control of failure. Other measures include intravenous aminophylline for the rapid relief of acute left ventricular failure, for the enhancement of the action of mercurial diuretics, and, in repeated doses every 4 to 6 hours, for the control of the occasional case of resistant chronic left ventricular failure. Large pleural or peritoneal accumulations of fluid often warrant paracentesis, while massive pitting œdema of the legs which resists other measures should be treated by acupuncture or Southey's tubes. If antibiotics are given, infection is rarely a problem, while the adverse effects of rapid fluid loss described by Vere and King (1960) must be rarely encountered.

The great majority of cases respond excellently to treatment. A weight chart should always be kept, as this provides much more reliable information than estimates of urine volume in the in- $\frac{\pi}{1}$ continent. When the response to treatment is inadequate, the whole situation must be reviewed. The diagnosis must be considered, to see that it is $\stackrel{\vec{O}}{\circ}$ both correct and complete, i.e. that no other con- $\overline{0}$ dition has been overlooked. The most important $\frac{}{}$ complications are respiratory infection, pul- $\frac{\bar{D}}{\frac{1}{6}}$ monary embolism, and the development of a $\mathbb{\otimes}$ biochemical disorder, often as a sign of a complication, or of a coxisting condition such as chronic renal disease (almost always chronic pyelonephritis) or hypoproteinæmia. The commonest biochemical disorder is hyponatræmia (serum sodium concentration less than $130 \mathrm{mEq}$./1.), which may be the expression of one of several basic disturbances (Elkinton, 1956). These include water retention (Hanenson, Goluboff, Grossman, Weston, and Leiter, 1956), sodium depletion (Schroeder, 1949), and potassium depletion (Cort and Matthews, 1954); the first signifies very severe heart failure and is usually fatal, the second responds dramatically to salt replacement, and the third should be prevented by giving adequate potassium supplements with all diuretics.

The prevention of recurrence of heart failure dependent on the prevention of precipitating factors, but an essential part is played by regula and detailed clinical examination at intervals of not less than three months. Particular attention must be paid to orthopnœa, asthenia, insomnia, and cough, as early symptoms of recurrence. Digitalis should be continued for six months if the cause of failure is transient, and indefinitely if it is persistent. Diuretics should be continued so long as there are any symptoms or signs of actual or incipient failure.

The prognosis of congestive failure in old age has been found to be better than was thought (Bedford and Caird, 1956); $27 \%$ survive two years, and $16 \%$ four years. In only one-third does death occur from heart failure or with heart failure still present. In fact, much of the mortailty is due to illness sufficiently severe to necessitate admission to hospital, rather than to heart failure itself (Bedford and Caird, r960). The true prognosis of all cases, such as might be seen in general practice, must be substantially better.

It is a pleasure to thank Drs. J. R. A. Mitchell, K. F. R. Schiller, T. B. Stephens and L. Wollner for their advice and criticism. Figures 2 to 8 are reproduced by kind permission of Messrs. J. \& A. Churchill Ltd. 


\section{REFERENCES}

Abdin, E. H. (1958): The Electrocardiogram in Aortic Stenosis, Brit. Heart Y., 20, 31.

ANDERSON, H. J., and StAFfurTh, J. S. (1955): Subacute Bacterial Endocarditis in the Elderly, Lancet, ii; 1055.

Anderson, M. W., Kelsey, J. R., and Edwards, J. E. (1952): Clinical and Pathological Considerations in Cases of Calcific Aortic Stenosis, f. Amer. med. Ass., 149, 9.

Anderson, W. F., and Cowan, N. R. (1959): Arterial Pressure in Healthy Older People, Clin. Sci., 18, 103.

Ashworth, C. T. (1946): Atherosclerotic Disease of the Heart, Arch. Path., 42, 285.

BAcon, A. P. C., and MATTHEwS, M. B. (1959): Congenital Bicuspid Aortic Valves and the Ætiology of Isolated Aortic Valvular Stenosis, Quart. F. Med., N.S., 28, 545.

BechgaARD, P. (1946): Arterial Hypertension: A Follow-up Study of One Thousand Hypertonics, Acta med. scand., Suppl. 172.

BEDFORD, P. D. (1950): A Simple Low-Sodium Regime, Lancet, ii, 823.

, and CAIRD, F. I. (1956): Congestive Heart Failure in the Elderly, Quart. Y. Med., N.S., $25,407$.

- 1 ( 1960$)$ : 'Valvular Disease of the Heart in Old Age'. London: J. \&.A. Churchill.

BJorck, G. (1962): Course and Prognosis in Some Cardiac Diseases, f. chron. Dis., 15, 9.

, Sievers, J., and Blomevist, J. (1958): Studies in Myocardial Infarction in Malmo, 1935-54 (III), Acta med. scand., 162, 81.

Bruns, D. L., and van Der Hauwert, L. G. (1958): The Aortic Systolic Murmur Developing With Increasing Age, Brit. Heart F., 20, 370.

Byrne, J. J., and O’Neil, E. E. (1952): Fatal Pulmonary Emboli, Amer. F. Surg., 83, 47.

Campbell, E. J. M., and Howell, J. B. L. (1960): Simple Rapid Methods of Estimating Arterial and Venous $\mathrm{PcO}_{2}$, Brit. med. Y., i, 458.

Carroll, D. (I95I): Non-traumatic Aortic Valve Rupture, Bull. Fohns Hopk. Hosp.s 89, 309.

CATES, J. E., and Christie, R. V. (195I): Subacute Bacterial Endocarditis, Quart. F. Med., N.S., 20, 93.

Clark, W. S., Kulka, J. P., and BaUer, W. (1957): Rheumatoid Aortitis with Aortic Regurgitation, Amer. F. Med., 22, 580.

Clawson, B. J. (1951): The Heart in Essential Hypertension. In 'Hypertension', p. 239. Ed. E. T. Bell. University of Minnesota.

Colmers, R. A. (1958): Atrial Septal Defects in Elderly Patients, Amer. F. Cardiol., r, 768.

CoRT, J. H., and Matthews, H. L. (1954): Potassium Deficiency in Congestive Heart Failure, Lancet, i, 1202.

Cutforth, R. H., and Oram, S. (1958): The Electrocardiogram in Pulmonary Embolism, Brit. Heart Y., 20, 41.

Dall, J. L. C., and Buchanan, J. (1962): Steroid Therapy in Heart Block Following Myocardial Infarction, Lancet, ii, 8.

Davies, C. E., and Steiner, R. E. (1949): Calcified Aortic Valve: Clinical and Radiological Features, Brit. Heart Y., II, 126.

Davis, B. T. (1962): Accessory Cusps of the Mitral Valve as a Cause of Mitral Regurgitation, Ibid., 24, 792 (Abstract).

DotTER, C. J., and Steinberg, I. (1949): The Angiocardiographic Measurement of the Great Vessels, Radiology, 52, 353 .

Elkinton, J. R. (1956): Hyponatræmia: Clinical State or Biochemical Sign, Circulation 14, 1027.

Fisch, C., Genovese, P. D., Dyke, R. W., Laramore, W., and MARvel, R. J. (1957): The Electrocardiogram in Persons Over 70, Geriatrics, 12, 616.

FLiNT, F. J. (1954): Cor Pulmonale: Incidence and Etiology in an Industrial City, Lancet, ii, $5 \mathrm{I}$.

Fox, T. T. (1944): On the Significance of the Normal Electrocardiogram in Old Age, Ann. intern. Med., 31, 20.

GleCKLER, W. J. (1958): Diagnostic Aspects of Subacute Bacterial Endocarditis in the Elderly, Arch. intern. Med., I02, 761.

Goodwin, J. F., Harrison, C. V., and Wilcken, D. E. L. (1963): Obliterative Pulmonary Hypertension and Thromboembolism, Brit. med. $\mathcal{Y} .$, i, 701 .

Gould, S. E., and CAWLEY, L. P. (1958): Unsuspected Healed Myocardial Infarction in Patients Dying in a General Hospital, Arch. intern. Med., ror, 524.

Gouley, B. A., and Sickel, E. M. (1943): Aortic Regurgitation Caused by Dilatation of the Aortic Orifice and Associated with a Characteristic Valvular Lesion, Amer. Heart f., 26, 24.

Griffith, G. C., Stragnell, R., Levinson, D. C., Moore, F. J., and Ware, A. G. (1952): A Study of the Beneficial Effects of Anticoagulant Therapy in Congestive Heart Failure, Ann. intern. Med., 37, 867.

Hanenson, I. B., Goluboff, B., Grossman, J., Weston, R. E., and Leiter, L. (1956): Studies on Water Excretion Following Intravenous Hydration and the Administration of Pitressin or Nicotine in Congestive Heart Failure, Circulation, 13, 242.

Hass, G. E. (1942): Elastic Tissue (II), Arch. Path., 34, 97 I.

(1943): Elastic Tissue (III), Ibid., 35, 29.

Honey, G. E., and Truelove, S. C. (1957): Prognostic Factors in Myocardial Infarction, Lancet, i, 1209.'

Hughes, W., Dodgson, M. C. H., and MacLennan, D. C. (1954): Chronic Cerebral Hypertensive Disease, Ibid., ii, 77 r.

KarSner, H. T., and Koletsky, S. (1947): 'Calcific Disease of the Aortic Valve'. Philadephia: J. B. Lippincott.

Kincaid-Smith, P., McMichaeL, J., and MURPHY, E. A. (1958): The Clinical Course and Pathology of Hypertension with Papillœedema (Malignant Hypertension), Quart. $\mathcal{F}$. Med., N.S., 27, 117.

Kinsey, D., and WhITE, P. D. (1943): Fever in Congestive Heart Failure, Arch. intern. Med., 65, 163.

LEONARD, J. C., and SMITH, W. G. (1957): Syphilitic Aortic Incompetence, Lancet, i, 234.

Levine, E., STEIN, M., Gordon, G., and Mitchell, N. (1951): Chronic Dissecting Aneurysm of the Aorta Resembling Chronic Rheumatic Heart Disease, New Engl. $\mathcal{~}$. Med., $244,902$.

Lown, B., and Levine, S. (1955): 'Current Concepts in Digitalis Therapy'. London: J. \& A. Churchill.

MASTER, A. M., LASSER, R. P., and JAfFe, H. L. (1958): Blood Pressure in White People Over 65 Years of Age, Ann. intern. Med., 48, 284 .

Matthews, M. B., and Hampson, J. (1958): Hepato-jugular Reflux, Lancet, i, 873. 
Macfarlane, M. V., Swan, W. G. A., and Irvine, R. E. (1956): Cardiovascular Disease in Syphilis, Brit. med. f., i, 827 .

McMichael, J., and Parry, E. H. O. (1960): Prognosis and Anticoagulant Prophylaxis After Coronary Occlusion, ₹ Lancet, ii, 991.

Mrtchell, J. R. A., and Schwartz, C. J. (1963): The Relation Between Myocardial Lesions and Coronary Artery Disease (III), Brit. Heart Y., 25, 1.

Muller, C. (1956): Aortic Stenosis and the So-called Rheumatic Valvular Diseases in a Post-mortem Material, Acta $\overrightarrow{\bar{B}}$ med. scand., $156,241$.

OLIVER, M. F., and BOYD, G. S. (1959): Effect of Bilateral Ovariectomy on Coronary Artery Disease and Serum Lipid Levels, Lancet, ii, 690.

Peery, T. M. (1942): Incomplete Rupture of the Aorta, Arch. intern. Med., 70, 689.

Penton, G. B., Miller, H., and Levine, S. A. (1956): Some Clinical Features of Complete Heart Block, Circulation, 13, 801 .

Portal, R. W., Davies, J. G., Leatham, A., and Siddons, A. H. M. (1962): Artificial Pacing for Heart Block. Lancet, ii, 1369 .

Rose, G. A., and WiLson, R. R. (1959): Unexplained Heart Failure in the Aged, Brit. Heart F., 21, 511.

SANDleR, G., and Wilson, G. M. (1959): The Nature and Prognosis of Heart Disease in Thyrotoxicosis, Quart. $\mathcal{F}$. Med., N.S., 28, 347 .

ScadDing, J. G. (1960): Chronic Diffuse Interstitial Fibrosis of the Lungs, Brit. med. F., i, 443.

ScHROEDER, H. A. (1949): Renal Failure Associated with Low Extra-cellular Sodium Chloride, $\dot{\mathcal{y}}$. Amer. med. Ass. I4I, 117.

SchwarTz, C. J., and Mitchell, J. R. A. (1962): The Relation Between Myocardial Lesions and Coronary Artery Disease (I), Brit. Heart Y., 24, 761.

SevitT, S., and Gallagher, N. G. (1959): Prevention of Venous Thrombosis and Pulmonary Embolism in Injured Patients, Lancet, ii, 981 .

SharPeY-Schafer, E. P. (1945): Transfusion and the Anæmic Heart, Ibid., ii, 297.

SHIRLEY-SMITH, K. (1960): The Kinked Innominate Vein, Brit. Heart Y., 22, 1 ro.

SHORT, D. S. (1951): A Radiological Study of Pulmonary Infarction, Quart. F. Med., N.S., 20, 233.

SIEvers, J., BlomQvist, G., and BJORCK, G. (1961): Studies in Myocardial Infarction in Malmo, 1935-54 (VI), Acta med. scand., 169, 95.

SLEIGHT, P. (1962): Unilateral Elevation of the Internal Jugular Pulse, Brit. Heart f., 24, 726.

STOREY, G. (1958): The Electrocardiogram in Syphilitic Heart Disease, Ibid., 20, 483.

SUTER, F. (1897): Ubber das Verhalten des Aortenumfanges unter physiologischen und pathologischen Bedingungen, Arch. exp. Path. u. Pharmakol., 39, 289.

Tench, W. R. (1955): The Triad of Tachycardia, Digitalis Toxicity, and Mercurial-fast Edema in Congestive Heart Failure Complicated by Pulmonary Embolism, Amer. F. Med., 18, 869.

Thorner, M. C., Carter, R. A., and Griffith, G. C. (1949): Calcification as a Diagnostic Sign of Syphilitic Aortitis, Amer. Heart Y., 38, 641.

Towbin, A. (1954): Pulmonary Embolism: Incidence and Significance, f. Amer. med. Ass., 156, 209.

VERE, D. W., and KING, C. E. (1960): The Reaction to Subcutaneous Drainage in Anasarca, Lancet, i, 779.

Webster, B., Rich, C., Densen, P. M., Moore, J. E., Nicol, C. S., and PAdGet, P. (1955): Studies in Cardiovascular Syphilis (III), Amer. Heart Y., 46, 117.

WeDGwOOD, J. (1955): Early Diagnosis of Subacute Bacterial Endocarditis, Lancet, i, 1058.

Wiggers, C. J. (1932): Physical and Physiological Aspects of Arteriosclerosis and Hypertension, Ann. intern. Med., 6, 12 .

Wilens, S. L. (1937): The Post-mortem Elasticity of the Adult Human Aorta, Amer. F. Path., 13, 811.

Wosika, P. H., FELdwan, E., Chesrow, E. J., and MYers, G. S. (1950): Unipolar Precordial and Limb Lead Electrocardiograms in the Aged, Geriatrics, $5,131$.

Zeman, F. D. (1945): Subacute Bacterial Endocarditis in the Aged, Amer. Heart Y., 29, 66r. 